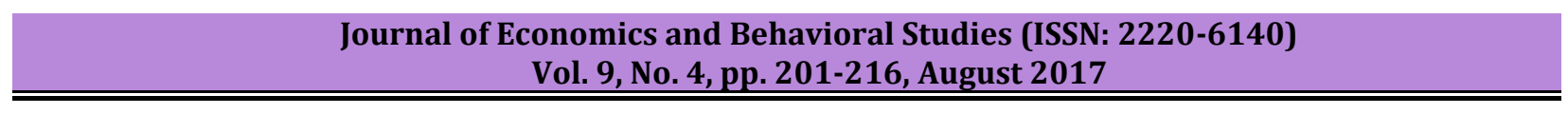

\title{
The Time Preference of Chinese Tend to be Less Affected by Positive Emotions: As Proved by an Experimental Study
}

\author{
Shi Yingnan ${ }^{1}$, Xinghao $\mathrm{Li}^{2}$ \\ ${ }^{1}$ College of Business and Economics, the Australian National University, Canberra, Australia \\ ${ }^{2}$ University of Michigan, Ann Arbor, MI, United States of America \\ u5755653@anu.edu.au,Xinghli@umich.edu
}

\begin{abstract}
This paper aims at testing whether positive emotions have a different impact on Chinese participants' time preference choices from American respondents on average, considering that the Chinese people own a different culture background and more inward-oriented national characteristic. The researcher conducted a controlled experiment based on random assignments, and the experiment is specifically adapted for Chinese participants. Further, in order to approach to a more accurate result, the research also determines such effect is influenced, if any, by personality factors such as risk preference. The BDM (Becker-DeGrootMarschak) and an MPL (Multiple Price List) methods were utilized to gather sufficient data and to ensure accurate measures. This paper indicates that, on average, for a Chinese participant, positive emotion will still reduce their time preference over intertemporal decision regarding to cash payment, but in a smaller amount on average, compared to an American respondent. Also, the result shows that, risk preference does play a role and tend to risk neutral persons have a weaker time-preference, compared to risk-takers and risk-avoiders. Moreover, several other factors, such as the health state, family income, and gender may also have correlation with time preferences. Alternative explanations are proposed at the end. This research may contribute to explain the differences of credit card usages preferences between the Chinese and American consumers and to explicate the reasoning of the Chinese economic miracles in the recent decades.
\end{abstract}

Keywords: Emotions; Time Preference; Risk Preference; Behavioral Economics; Decision Makings

\section{Introduction}

The majority of the people succumb to their emotions when they are making economic decisions, at least for some times. Time preference decisions, as one of the economic decisions, are certainly not an exception. Time Preference (TP),or time discounting, refers to a relative valuation based on a "present" date compared with the valuation at a "future" date. It is quantitatively measured by a Discounting Factor (DF), denoted D. Notably, DF is different from the discounting rate utilized in the financial fields. In this paper, if the discounting factor is large, the time preference is high, which is the convention of the economic study, and this economic research will follow such convention. In this experiment, the respondents who have a high time preference are to be satisfied with a smaller amount of cash (being paid at present)against a larger amount of income to be reimbursed in a future. On the other hand, if the discounting factor is low, the person's time preference is, therefore, weak. The participant hence needs a larger amount of "immediate" money to reimburse the payment to be paid in the future.

Early in the 19th century, Senior (1836), Jevons (1888), and Jevons (1905), observed that a typical individual's TP is affected by factors including personalities (e.g. "benevolent affections") and moods (e.g. "risk preference", "self-restrains", and "abstinences") Their qualitative research stated that people tend to chase long term investment when they are happier and more comfortable and to pursue short-term enjoyment when they are in unhealthy and hazardous situations. Later experiments, as in Loewenstein (1996, 2000)'s research, provide us further quantitative proofs which prove that the "visceral" influences, such as physical pains or positive emotions, would significantly affect people's intertemporal choices. Based on American respondents, Ifcher and Zarghamee (2011), conducted an experiment and verified that American people tend to concentrate more on future value rather than present value when they are in relatively positive moods. Also, in former researches, it has been found that on average Chinese people have different risk preference patterns from typical Americans (Hsee and Weber, 1999; Zhou et al., 2012) and a greater degree of emotional moderation than other cohorts. (Leung and Lind, 1986; Chiu and Kosinski, 1994; Russell and Yik, 1996) Therefore, it is reasonable to deduce that the effect of emotional changes will exert less changes in TP among Chinese participants. 
This research conducted a customized experiment at and collected data from a Chinese college located in Zhuhai, Guangdong, P. R. China. Section 4 introduces the detailed customization made for Chinese context. The significances of this experiment are:

The result of the experiment shows that the emotion's effect on Chinese respondents is evidently smaller: Endurance is a merit, and low time preference (high endurance) has been long deemed be beneficial for a person's and even a nation's (i.e. a large group or collective of people with common characteristics) long term development. It is often linked to future success. (Mischel et al., 1989) The conclusion of this paper may contribute to explain the reasoning of Chinese economic miracles in recent three decades.

Time preference factors can be utilized to predict issues such as repayment of credit cards, marketing strategies and sales of prepaid coupons, and unhealthy eating (DeSteno et al., 2014). Result of this research may also contribute to those industries high relying on credit card transactions and coupons selling. Also, differences in time preference may help to explain why Chinese and American people have different consuming patterns.

By taking risk preferences into consideration, the study shows that, Chinese risk-neutral respondents have a lower time preference, compared to both risk taking and risk aversion groups. Moreover, changes enlarge when imposing a positive emotion inducement.

There are six sections in this paper, including an introduction contained in Section 1, and literature review in Section 2, an introduction of hypothesis, framework, and a model illustration in Section 3, a data collection and description part in Section 4. The alternative analysis is in Section 5. Section 6 offer conclusions and further discussions.

\section{Literature Review}

Time Discounting and Preference: Samuelson (1937) first utilized Discounted Utility and condensed "time preference" into a generalized model for "intertemporal choices" with only one single parameter - discount rate. Notably, the DU model is based on several very strong assumptions which are challenged by many economists for many years. For example, one of the assumptions is the discount effect should be linearly consistent, regardless of the length of the time period. However, there exist anomalies, such as the "hyperbolic discounting anomaly" effect and the "magnitude effect anomaly" effect, which should be considered by this research. Firstly, the "hyperbolic discounting anomaly" effect indicated that a smaller time horizon offers a higher sensitivity in regard to time discounting. Thaler (1981) observed the fact that rewards that have a longer time horizon are discounted less than short time horizons. A hyperbolic model is a better fit the data than an exponential one (Kirby, 1997). The anomaly can be clearly illustrated by graphs provided by Frederick, Loewenstein, and O'donoghue (2002) as seen in the following chart. Secondly, the "magnitude effect anomaly" effect indicated that outcomes of the smaller amount should as well be more sensitive. Ainslie and Haendel (1983), Benzion, Rapoport, and Yagil (1989), Holcomb and Nelson (1992), Kirby and Marakovic (1995), and Kirby (1997) mentioned that the changes in outcomes of the small amount will be discounted more than that in a large amount.

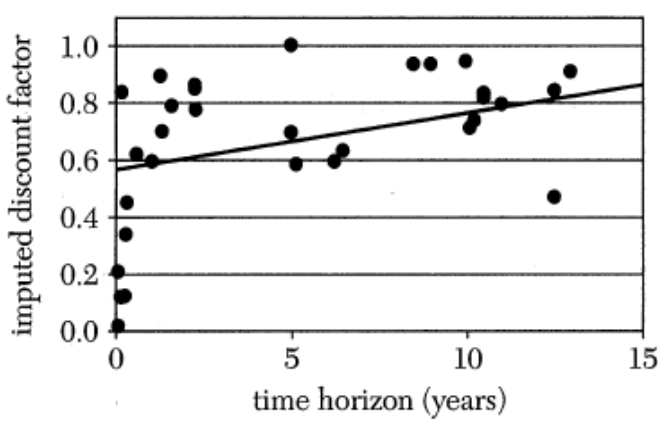

Figure 1a. Discount Factor as a Function of Time Horizon (all studies)

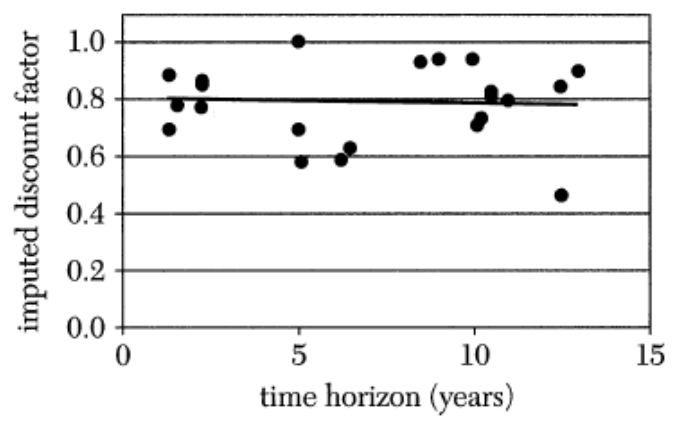

Figure 1b. Discount Factor as a Function of Time Horizon (studies with avg. horizons $>1$ year) 
As shown in Figure 1a and 1b, since the experiment in this paper is a "small outcome with-in a short time horizon" one, which enabled the respondents participating our research to provide answers of a greater degree of sensitiveness. Therefore, the distortion effects of the anomalies shall be minimized.

Positive Emotion and Time Preferences: Emotions influence people's behavior in a way that may have a significant impact on people's decision making process. Kahneman and Tversky (1979) and Loewenstein and Prelec (1992) initiated and applied the prospect theory and proved that, intuitively, people are responsive to their emotional reactions rather than rational activities. Therefore, they will adjust their prospected satisfactions according to the changes in moods. In recent years, many economic behaviors have been affected by emotions, and there are an increasing number of experiments which prove that idea. For example, positive emotions enhance productivity (Ifcher and Zarghamee, 2011), loss aversion (Isen, Nygren and Ashby, 1988), and cognitive flexibility (Isen, 2008). Moreover, Hermalin and Isen (2001) illustrated the effect of emotion on economic decisions and strategic choices. Isen (2001) and Isen (2007) also pointed out that positive emotions will improve people's ability of self-control and their forward-looking capacity. Time preference, as a particular kind of economic decision, is influenced by individuals' moods change. For instance, in earlier empirical observations (both from the observation of General Social Survey and from economist's observation). Ifcher and Zarghamee (2011) qualitatively concluded the existence of such causal relationships and quantitatively examined that the happier people have a higher discount rate than people in neutral moods or bad moods.

However, Keltner, Haidt, and Shiota (2006) indicate there are too many "specific but different" feelings in the name of "positive or negative emotion" category, and, therefore, the concept that all negative/ positive emotions leading to the same tendency of impatience/ patience is questionable. For instance, Desteno et al. (2014) tested and concluded that, both happiness and gratefulness, undoubtedly positive emotions, would lead to different discount rates. Therefore, it is essential to explicit and to distinguish what particular positive emotions the experiment would inspire. Highly accurate and specific emotion inducing method is therefore needed. The paper mainly referenced to the study of Riedl and Wölbert (2013) and Fishburn and Rubinstein (1982) about how to measure time preference. As a matter of fact, time preference, as an abstract economic term, was once hard to measure. Fortunately, many efforts have been devoted to finding ways of estimating and of measuring time preference. To reliably test that variable, we therefore also read works from Benhabib and Bisin, (2005); Laibson, (1997); Coller and Williams, (1999); Fisher, (1930); Gul and Pesendorfer, (2001); Harrison, Lau, and Williams (2002); Hausman, (1979); Loewenstein and Prelec, (1992); Rubinstein, (2000); Thaler and Shefrin, (1981); O'Donoghue and Rabin, (1999); Warner and Pleeter, (2001) for references. Moreover, the determination of and measurement of time preference was discussed by Thaler (1981), and Kriby and Marakovic (1996).

Happiness Inducement Approaches: At least eight moods-inducement methods have been proved effective in inducing people's emotions in an experimental environment (Jiang, Chen, and Chen 2011). The researcher reviewed all of them in our pilot testing and found the most effective one is short film clips This method was first introduced by Gross and Levenson (1995) and is now being commonly used both in the psychology and in the economics field. The formal experiment used Chinese movie clip because Jin (2009) and Peng (2012) indicated that people from different countries react to the inducement methods differently. Hence, it is essential for us to choose befitting film clips in order to adapt to our subjects, the Chinese people.

Personality (Risk Preference/Aversion) and Preferences: Individuals' personalities, such as risk aversion and risk taking, may influence the time preference. Zhou et al. (2012) stated that Chinese people have different risk preference patterns from foreigners. Borghans et al. (2008) generalized the relevance between economics and people's personality traits. Andersen et al. (2008) conducted verified the effect of risk averseness on time preference. On top of that, Rabin and Thaler (2001) alerted researchers conducting experimental economics that they should be concerned with its impact or the result could be "misleading". Zaleskiewicz (2001) stated that investment preferences will be influenced by people's personalities. Personalities, moreover, will have an impact on the individual's rational thinking capability, impulsiveness, and sensation seeking behaviors. Hence, in this research, we put people's tendency towards riskiness into consideration, which is tested by MPL method in the study. The method is created by Holt and Laury (2002) and was proved effective in China by Zhou et al. (2012). For the purpose of this paper, national characteristics 
refer to a sociological concept and are utilized to make comparisons between the Chinese and American participants' results. Personality, on the other hand, is a psychological term, and it is used as a manipulated variable.

\section{Hypothesis\& Model}

H1: Watching a funny short video would evidently raise the degree of happiness.

Short funny videos can induce positive emotions. Jiang, Chen and Chen (2011) introduced that one of the most effective of inducing moods is utilizing film clips.

H2: People who have a personality of risk neutrality tend to have a higher TP.

Andersen et al. (2008) argued that risk-averseness will influence people's time preference. Driven by insecurity about the future, people who have a higher tendency towards risk averseness may discount more when they are comparing present incomes and future incomes, which indicates that they tend to have a higher time preference (Caplin \& Leahy, 2001). Also, risk-taking people may write a larger number in the present value column so as to obtain a higher return, though with a higher risk.

H3: Males tends to have lower time preference than females.

Croson and Gneezy (2009) stated that preferences between females and males tend to be very different. Although Ifcher and Zarghamee (2011) argued that males tend to have higher time preference than females (in a tiny amount), Tanaka, Camerer, and Nguyen (2010) argue that in Vietnam, a much similar-to-China state, males tend to behave more patient and thus to have lower time preference.

H4: Family income has a negative relationship with time preference.

Family wealth status affects people's time preferences. Frederick, Loewenstein \& O'donoghue (2002) mentioned that people from richer families tend to focus more on future payment.

H5: The healthier the people, the lower the mean time reference.

The heath condition may also affect people's time preference. It is logical to argue that a dying person, in an extreme case, tends to have higher time preference than a healthy person. Fuchs (1980) also stated that health condition may affect people's time preference.

H6: For an average Chinese person, positive emotions, such as happiness, has smaller mean impact on time preference changes.

Chinese people's emotions have less influence power on their time preference decisions, which may be caused by a difference in national characteristics from American and by different risk preferences.

Model: First, as Ifcher and Zarghamee (2011) demonstrated, positive mood significantly increases the present value (p) of a fixed future payment $(\mathrm{m})$, that is, there is a relationship between the positive affect and time preference. Second, the present value $(\mathrm{p})$ is also influenced by the given amount of the future payment $(\mathrm{m})$, the expiration to get the payment $(\mathrm{t})$, and their joint effects, that is, the present value is considered to be a function of $m, t$, and $m^{*} t$. Besides, the effects of some demographic factors, such as subjects' personalities and their knowledge toward Economics, on the present value they determined could not be neglected. Based on the above explanation, the regression can be demonstrated like this:

$\mathrm{p}=\beta_{0} H+\sum_{r} \gamma_{r} I_{R}(r)+\sum_{g} \eta_{g} I_{G}(g)+\sum_{i} \pi_{i} I_{I}(i)+\sum_{h} \rho_{h} I_{H}(h)+\varepsilon$

His a dummy for the positive-affect-inducing treatment, all future payment amounts mare included in the set of $M$, all time delays $t$ (in days) are included in the set of $T$, and $p$ is the subjective present value of $\$ \mathrm{~m}$ in $\mathrm{t}$ days. For a given $\mathrm{m}$ and $\mathrm{t}$, the functions $I_{M}(m)$ and $I_{T}(t)$ take the value of one, respectively, and zero otherwise; this specification allows for all possible linear and joint effects of $t$ and $m$ on discounting. The model also includes demographic factors, risk preference, gender, family income, and health state. For 
example, $I_{G}=$ gender, where $g \in\{$ male, female $\}$, and $I_{G}(g)$ equals one if the participant is male, and zero otherwise. Besides, ${ }_{0}$ is constant.

$I_{R}(r)$ is a dummy variable for participants' risk preference (risk-taking, risk-averse and risk-neutral), using risk aversion as a base group.

$I_{G}(g)$ is a dummy variable for participants' gender (male and female), using female as a base group.

$I_{I}(i)$ is a dummy variable for participants’ family income (below $¥ 100,000$, between $¥ 100,000$ and $¥ 200,000$, and beyond $¥ 200,000$ ), using participants whose family income is higher than $¥ 200,000$ as a base group.

$I_{H}(h)$ is a dummy variable for participants' health state (excellent, very good, good, fair, and poor), using participants whose health state is good as a base group.

\section{Methodology}

Before the experiment: Researchers attempted to make the experiment as official as they can. For example, a social media account was utilized to summon participants. Every participant would receive a message which stated the experiment date, seat number, and session number, etc. All of the information was provided in an official and formal tone.

Chinese customization: Four major adoptions are made for Chinese context: (1) Chinese movies are selected to replace the American ones. A pretest was run before the formal experiment to ascertain the effectiveness of moods inducement movie flips. (2) All the experiment instruments, such as the questionnaires, the explanatory notes, and the illustration videos, are translated into Chinese. The translation's quality was assured by certificated professional interpreters. This procedure is of great importance because in the pretest, researchers found that the participants cannot understand the question sets because their English are not sufficient (3) RMB, in lieu of USD, is used in this experiment. The amount to money is referenced to local salary level. (4) All the communication channels, such as summoning respondents and reimbursing the participants, are in Chinese, and at the end of the experiment, we provide Chinese version of feedback to the participants.

During the experiment: First, before testing participants' evaluation of present value, p, under different conditions, researchers tested risk preference, which was believed to have a strong relationship with time preference. An MPL method was utilized and the specific procedures of the examining of risk preference will be illustrated in Term B. Second, when the risk preference test was done, we use the mood-inducement approaches, specifically discussed in Term C, to guide participants into different predetermined moods. Participants in the treatment group were expected to be in positive moods, and others in the control group were expected to be in neutral moods. Third, right after the mood-inducement procedure, subjects' choices of values of $p$ were concerned, and 15 time-preference questions were designed to get the values of $p$ in terms of different $m$ paid in $t$ days. The reason why the time-preference questions are tightly followed by the moodinducement treatment is that participants can, therefore, make decisions under the most effective period. Fourth, when the time-preference questions were finished, subjects would answer questions about their subjective well-being after the mood-inducing treatment, including eight questions concerning about basic psychological characteristics information. Ultimately, based on their responses to the 15 time-preference questions, payments would be determined by a Becker- DeGroot-Marschak (BDM) mechanism, which will be further explained in Term E, and participants would receive their certificates of guarantee with a corresponding amount of money and due day on it. They would go to the same office to collect their repayment. Therefore, the transaction cost for every individual participant will be the same.

Participants: 60 undergraduate students from the college were randomly selected, half of whom were randomly arranged into the treatment group, and they are required to accept the positive mood inducement by watching a funny video clip, and the rest of whom would look at a neutral-mood-inducing video clip. To 
eliminate bias, researchers purposely and disorderly arranged participants' seats number to make sure no familiar persons will sit together. Before the start, an information sheet is assigned to each participant explaining the following details. First, the experimenter emphasized that all of the final payments would exactly depend on their answers to the 15 time-preference questions so as to encourage themselves to offer the best answer. The 15 questions are: "how much money, ¥p, if you could receive today, would bring you the same utility if $\$ \mathrm{~m}$ compensated to you in another $\mathrm{t}$ days, as a result, both payments make you feel indifferent?" To avoid inducing any logic inferences, researchers used abstruse values of $\mathrm{m}$ (such 1.82 rather than 2, and 4.02 rather than 4)so that participants could not provide a value based on calculating an exactly accurate number but they were to provide a present value based on their real feelings. Moreover, in order to remove the ordering effect, we disarrange the question number of the questionnaire and make it hard to find a pattern of the matches between $\mathrm{m}$ and $\mathrm{t}$. Besides, with the avoidance of school holidays and weekends, the due days of $t$ were set within one academic term, thus dispelling the doubt that subjects might not receive their payments. Therefore, the combinations were determined as all matches of three values of $m,\{¥ 15.2$, $¥ 24.7, ¥ 30.8\}$, and four values of t, $\{24$ hours, 168 hours, 576 hours, 840 hours, 984 hours $\}$. Second, the participants were given guarantees of payment which record each participant's final payment amounts, $p$, and the corresponding due days, $t$, which were redeemable for the corresponding cash on that day off-site. Moreover, subjects, who were determined to redeem their payments on the same day of conducting the experiment, were paid within one hour after the accomplishment of the experiment.

Risk Preference Test-The method we utilized is illustrated as followed: There are two types of lotteries, Lottery A and Lottery B. Lottery A, also named secured item, owns two kinds of returns, and the spread of its higher level of return with the lower level of return is not very distant. On the other hand, Lottery B owns a larger risk spread, is designed for people who have a higher tendency of seeking risks. The probability of obtaining Lottery A and Lottery B is set in advance, which is shown in Table 4.3, a guide of the lottery game. As it can be seen in Table 4.3, in scenario 1, the person has $10 \%$ probability of gaining 2 yuan, and $90 \%$ of 1.6 yuan when he or she choose lottery A, and there are $10 \%$ chances of getting 3.85 but 90 percent of gaining only 0.10 when choosing lottery B. The rest of the table can be explained in the same manner. A person with high risk-seeking personality would choose B in his or her first chance of choice. Meanwhile, people who occupied a neutral personality in risks will choose B after the 4 th term.

Table 1: A Guide of the Lottery Game

\begin{tabular}{|c|c|c|}
\hline No. & Lottery A $(2,1.6)$ & Lottery B $(3.85,0.10)$ \\
\hline 1 & $1 / 10$ Get 2 | $9 / 10$ Get 1.6 & $1 / 10$ Get $3.85 \mid 9 / 10$ Get 0.10 \\
\hline 2 & $2 / 10$ Get $2 \mid 8 / 10$ Get 1.6 & $2 / 10$ Get $3.85 \mid 8 / 10$ Get 0.10 \\
\hline 3 & $3 / 10$ Get $2 \mid 7 / 10$ Get 1.6 & $3 / 10$ Get $3.85 \mid 7 / 10$ Get 0.10 \\
\hline 4 & 4/10 Get $2 \mid 6 / 10$ Get 1.6 & 4/10 Get $3.85 \mid 6 / 10$ Get 0.10 \\
\hline 5 & $5 / 10$ Get $2 \mid 5 / 10$ Get 1.6 & $5 / 10$ Get $3.85 \mid 5 / 10$ Get 0.10 \\
\hline 6 & $6 / 10$ Get $2 \mid 4 / 10$ Get 1.6 & $6 / 10$ Get $3.85 \mid 4 / 10$ Get 0.10 \\
\hline 7 & $7 / 10$ Get $2 \mid 3 / 10$ Get 1.6 & $7 / 10$ Get 3.85 | $3 / 10$ Get 0.10 \\
\hline 8 & $8 / 10$ Get $2 \mid 2 / 10$ Get 1.6 & $8 / 10$ Get $3.85 \mid 2 / 10$ Get 0.10 \\
\hline 9 & $9 / 10$ Get $2 \mid 1 / 10$ Get 1.6 & $9 / 10$ Get $3.85 \mid 1 / 10$ Get 0.10 \\
\hline 10 & 10/10 Get 2 | 0/10 1.6 & $10 / 10$ Get $3.85 \mid 0 / 10$ Get 0.10 \\
\hline
\end{tabular}

Mood-Inducement Procedure: Moods of subjects in the experimental group were trying to be manipulated by some conducts. Initially, according to Jiang, Chen and Chen (2011), there are seven approaches to induce positive and negative moods, memories, imagine, pictures, film clips, music mood-inducing method and the combination of emotional induction methods. After taking a pilot testing of a small group of observers, other than the experimental participants, we found film clips were the most useful method to induce positive mood, which complied with the conclusion drawn by Westermann, Stahl and Hesseet (1996) that the use of story or film was an effective method to induce positive affect. 30 of 60 participants, as the experimental group, were randomly selected to watch a clip extracted from a funny film to stimulate their positive emotion. The other 30 respondents are assigned to the control group with watching neutral-mood-inducing film clips. 
The successfulness of the mood-inducing conducts could be identified through a customized Positive and Negative Affect Schedule (PNAS) (1988). PANS originally tests ten emotions but we only select seven important items: including four positive ones (interested, excited, enthusiastic and activated) and three negative ones (distressed, nervous, upset). By comparing the results of two groups (the experimental and the control group), we could confirm that where the film clip made them happier, or whether the film clip pushed them in better moods. The PNAS test was conducted right after the time-preference questions were asked. During the test, the participants are asked to rate a Likert scale, ranging from 1 (Have the opposite feelings as described) to 5 (Have the same feeling as described), to describe the degree to which they had felt this way. By comparing the results of two groups, we can confirm that the film clips made the experimental group happier, and they are also not pushed in other moods.

Time-Preference Questions and Completing the Session: The participants were asked to answer the 15 timepreference questions, closely after the mood-inducement procedures, and then, subjects responded to queries about their moods. Subsequently, subjects filled up a form regarding their demographic characteristics. Then, the payments were determined by implementing the BDM mechanism, which would be introduced later. Finally, participants would receive cash or guarantee of reimbursements.

BDM Mechanism: After participants had accomplished the 15 time-preference questions, to determine each subject's final payments, a Becker-DeGroot-Marschak (BDM) Mechanism (Gordon et al., 1964) was utilized. The procedures were conducted as follows: $\mathrm{m}$ balls, numbered 1through $\mathrm{m}$, were placed in an opaque box. Each time, one ball was picked from the box.

If the number $R$ on the drawn ball was less than or equal to $p(R \leq p)$, then the subject was paid $\$ m$ in $t$ days; Otherwise, the subject will receive $\$ R$ on the day of the experiment.

For instance, for the match of $\mathrm{m}=¥ 13.8$ and $\mathrm{t}=4$ days, a subject determines $\mathrm{p}=9$. Now, putting 14balls, numbered 1through 14, are placed in an opaque box, the subject randomly (i) selects a ball with $R=7$, since $R$ is less than $p$, the subject would be paid $¥ 13.8$ in 4 days; (ii) selects a ball with $R=11$, since $R$ is greater than $p$, the subject would receive $¥ 11$ on the day of the experimental session. That is the final payment of the match $\mathrm{m}=¥ 13.8$ and $\mathrm{t}=4$ days for the subject. Since the procedures were complicated, the participants will receive a brief training session, ensuring the processes were completely comprehended.

\section{Results}

Table 2: Participants Exhibit Time Preference

Table1 --D(m,t) - Pooled group

\begin{tabular}{|c|c|c|c|c|c|c|}
\hline$¥ \mathrm{~m}$ & 1 & 7 & 24 & 35 & 41 & Mean \\
\hline 15.20 & 0.867 & 0.867 & 0.629 & 0.62 & 0.557 & 0.708 \\
\hline 24.70 & 0.855 & 0.736 & 0.615 & 0.593 & 0.552 & 0.670 \\
\hline 30.80 & 0.86 & 0.743 & 0.632 & 0.589 & 0.568 & 0.678 \\
\hline Mean & 0.861 & 0.782 & 0.625 & 0.601 & 0.559 & 0.686 \\
\hline \multicolumn{7}{|c|}{ Table2 --D(m,t) - Control group } \\
\hline & $\mathrm{t}$ days & & & & & \\
\hline$¥ \mathrm{~m}$ & 1 & 7 & 24 & 35 & 41 & Mean \\
\hline 15.20 & 0.831 & 0.695 & 0.593 & 0.617 & 0.522 & 0.652 \\
\hline 24.70 & 0.865 & 0.691 & 0.623 & 0.564 & 0.537 & 0.656 \\
\hline 30.80 & 0.852 & 0.722 & 0.615 & 0.585 & 0.533 & 0.661 \\
\hline Mean & 0.849 & 0.703 & 0.610 & 0.589 & 0.531 & 0.656 \\
\hline \multicolumn{7}{|c|}{$\begin{array}{c}\text { Table3 --D(m,t) - Treatment group } \\
\text { t days }\end{array}$} \\
\hline \multirow{2}{*}{$\begin{array}{l}¥ m \\
15.20\end{array}$} & 1 & 7 & 24 & 35 & 41 & Mean \\
\hline & 0.907 & 0.714 & 0.662 & 0.623 & 0.59 & 0.699 \\
\hline 24.70 & 0.845 & 0.781 & 0.607 & 0.621 & 0.565 & 0.684 \\
\hline
\end{tabular}




\begin{tabular}{|c|c|c|c|c|c|c|}
\hline \multicolumn{7}{|c|}{$\begin{array}{c}\text { Journal of Economics and Behavioral Studies (ISSN: 2220-6140) } \\
\text { Vol. 9, No. 4, pp. 201-216, August } 2017 \\
\end{array}$} \\
\hline 30.80 & 0.868 & 0.764 & 0.648 & 0.593 & 0.601 & 0.695 \\
\hline Mean & 0.873 & 0.753 & 0.639 & 0.612 & 0.585 & 0.693 \\
\hline
\end{tabular}

Given a future payment, $m$, in $t$ days, subjects feel indifferent to receive the amount $p$ today, yielding a discounting rate, $D=p / m$. Since discounting depends on the levels of $m$ and $t, D$ is a function of $m$ and $t$, which could be presented as $D=D(m, t)$. It's meaningless to purely compare the values of $p$, since the domain of $p$ is defined by the level of $m$, comparing $D$ makes sense. Table 1 provides all values of $D$ for all subjects both in the control group and the experiment group; Table 2 and 3 present $\mathrm{D}$ for the control group and the experiment group, respectively. Keeping $\mathrm{m}$ constant, the value of $\mathrm{D}$ in three tables tends to decrease as $t$ becomes larger and larger, and there are few exceptions in Table 2 and 3, where only one violation of the relationship between D and t exists in each table. Except fora few violations, the factor could still be inferred: Participants discount more heavily in the distant future than they do in the near future. To be visualized, Figure 1 demonstrates the pattern of $\mathrm{D}$ and $\mathrm{t}$, given each level of $\mathrm{m}$.

Figure 1: demonstrates the pattern of $\mathrm{D}$ and $\mathrm{t}$, given each level of $\mathrm{m}$

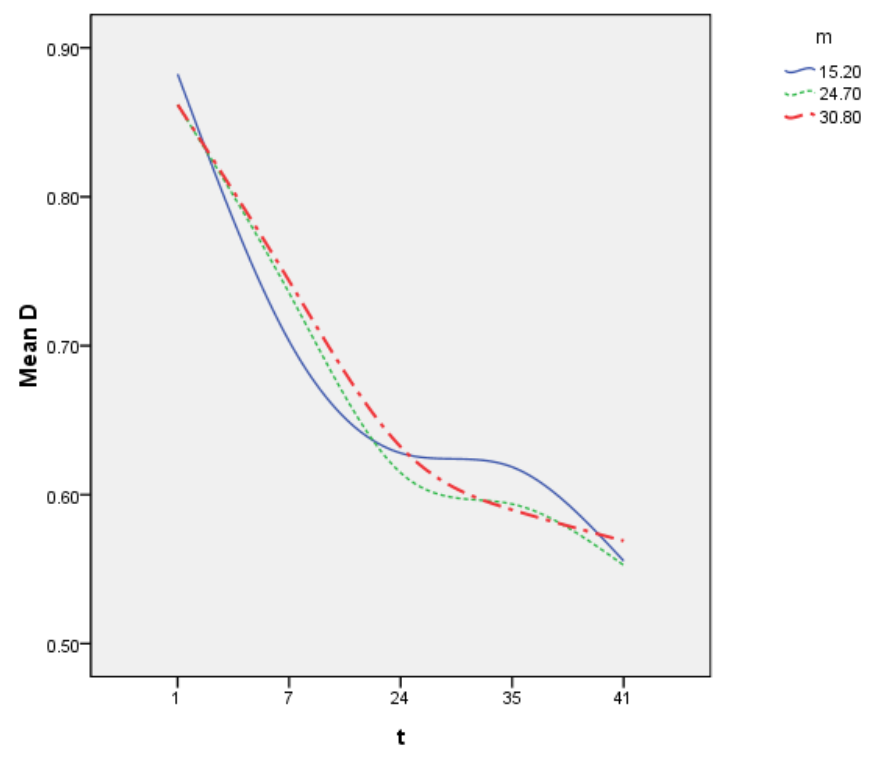

Keeping $\mathrm{t}$ constant, there is no clear relationship between $\mathrm{D}$ and $\mathrm{m}$, which means there is no monotonic pattern in $\mathrm{D}$ with respect to $\mathrm{m}$. For example, in Table 2, for $\mathrm{t}=1$, there is a $\mathrm{U}$-shape; for $\mathrm{t}=35$, there is a downward tendency.

Table 4: Net positive affect

\begin{tabular}{llll}
\hline Mean & & Treatment=1 & Treatment=0 \\
\hline PA (positive affects) & Interest & 4 & 2.393 \\
& Excitement & 3.034 & 2.112 \\
& Enthusiasm & 2.690 & 2.107 \\
& Activism & 3.276 & 2.531 \\
\multirow{2}{*}{ NA (negative affects) } & Distress & 1.759 & 2.495 \\
& Nervousness & 2.172 & 1.933 \\
& Upset & 2 & 2.143 \\
net positive affect & & 7.069 & 2.571 \\
\hline
\end{tabular}




\section{Journal of Economics and Behavioral Studies (ISSN: 2220-6140)}

Vol. 9, No. 4, pp. 201-216, August 2017

From Table 4, the net positive effect- the sum of the positive effects minus the sum of the negative effects from the PANAS - of participants in the treatment group (7.069) is evidently higher than that of participants in the control group $(2.571)$, and the $95 \%$ confidence interval of the difference for net positive affect in treatment group is $(4.2957,5.3292)$. To further identify the impact of affect-inducing treatment on D, Table 5 presents the differences of $\mathrm{D}$ in treatment group and control group under each combination of $\mathrm{m}$ and $\mathrm{t}$, the vast majority of which are positive.

Table 5: Dtreament(m,t) - Dcontrol(m,t)

\begin{tabular}{lllllll}
\hline$¥ \mathrm{~m}$ & $\mathrm{t}$ days & & & & \\
\hline $\mathrm{M}$ & 1 & 7 & 24 & 35 & 41 & Mean \\
15.20 & 0.076 & 0.019 & 0.069 & 0.006 & 0.068 & 0.0476 \\
24.70 & -0.02 & 0.09 & -0.016 & 0.057 & 0.028 & 0.0278 \\
30.80 & 0.016 & 0.042 & 0.033 & 0.008 & 0.068 & 0.0334 \\
Mean & 0.024 & 0.050 & 0.029 & 0.024 & 0.055 & 0.036 \\
\hline
\end{tabular}

Figure 2: $(m=15.2)$

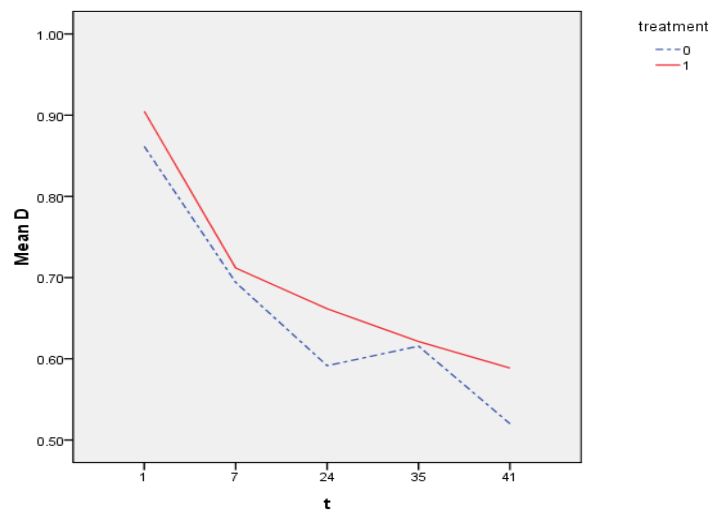

Figure 3: $(\mathrm{m}=24.7)$

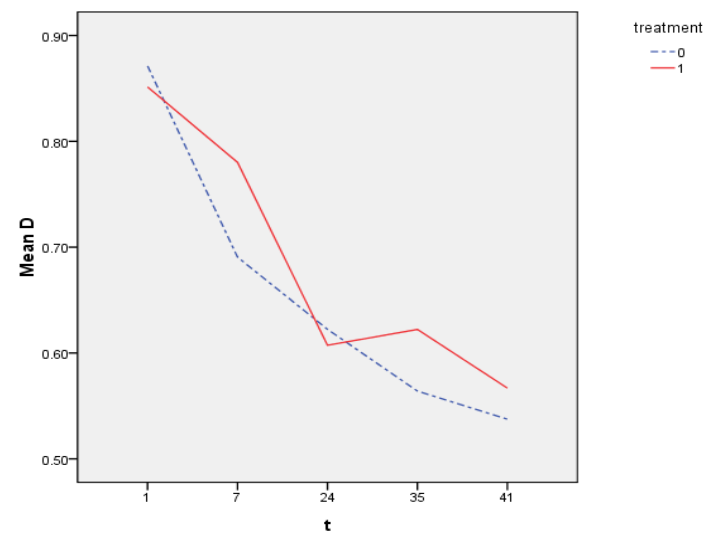


Figure 4: $(\mathrm{m}=30.8)$

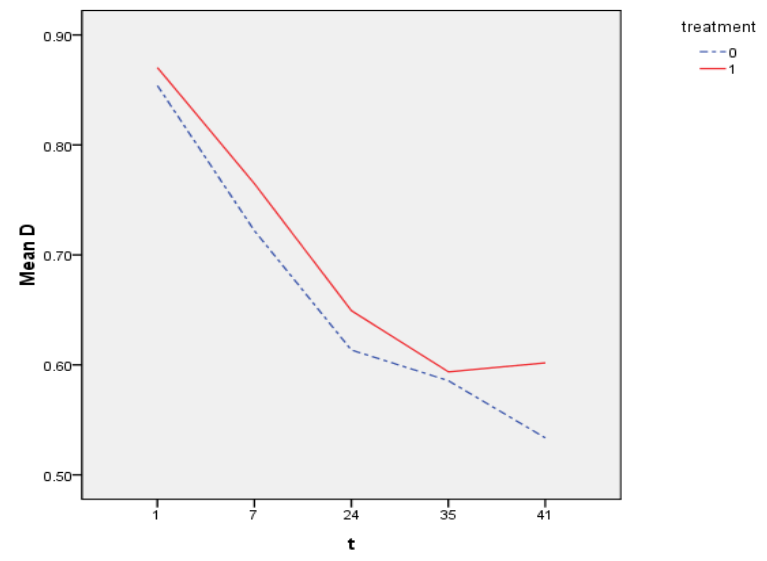

Figure 2, 3 and 4 is visualized to exhibit the relationship revealed in Table 5, and the two violations of differences in D are showed on Figure 3. Tables and figures above reveal that watching funny video clips made subjects significantly happier than those watching neutral-affect-inducing video clips, which supports the first hypothesis (H1); And most subjects in positive moods tend to discount more heavily than those in neutral moods, it means that positive-affect inducement reduces time preference, which supports the fifth hypothesis (H5).

Results of Estimating Equation: In column 1 of Table 6, demographic characters (gender, risk preference, family income and health state) are controlled, and dummy variables for treatment are excluded from the equation. Given $m$ and $t$, keeping other characters the same, averagely, (1) male would like to receive $¥ 1.87$ higher than female today; (2) people whose risk-neutral prefer ¥2.57 higher than those whose risk-averse today; (3) subjects whose family income are less than $¥ 100,000$ are willing to accept $¥ 2.5$ lower than those whose family income are huger than $¥ 20,000$ today; And health state shows an inverted U-shape. In column 2 , treatment is included into the equation based on column 1 , which significantly increases present value by 1.44 on average. Factors could be inferred from the results: (1) Comparing to people who are risk-aversion, people who are risk-neutral value higher present payment and present lower time preference, which supports the second hypothesis(H2);(2) Male would like to receive¥2.02 higher of present payment than female do, having a larger discount and lowering the time preference, which supports the third hypothesis (H3); (3) Comparing to people whose family income is larger than $¥ 200,000$, people, whose family income is less than 100,000 value lower present payment and present higher time preference, which support the fourth hypothesis (H4); (4) In terms of health state, from excellent to good state, there is a upward tendency, valuing higher present payments and lowering time preference, which support the fifth hypothesis (H5); From good to poor state, there is a downward tendency, valuing lower present payments and increasing time preference, which rejects the fifth hypothesis (H5).

Table 6: Summary (Dependent variable is present value, $p$ )

\begin{tabular}{llll}
\hline & & $(1)$ & $(2)$ \\
\hline Treatment & & -- & $1.44^{* * *}$ \\
Gender & & & $(0.49)$ \\
& & $1.87^{* * *}$ & $2.02^{* * * *}$ \\
Risk preference & Risk-averse & $(0.55)$ & $(0.55)$ \\
& Risk-neutral & 0 & 0 \\
& & $2.57^{* * *}$ & $2.91^{* * *}$ \\
& Risk-taking & $(0.70)$ & $(0.71)$ \\
& & -0.50 & 0.24 \\
& & $(0.54)$ & $(0.59)$
\end{tabular}




\begin{tabular}{|c|c|c|c|}
\hline \multicolumn{4}{|c|}{$\begin{array}{c}\text { Journal of Economics and Behavioral Studies (ISSN: 2220-6140) } \\
\text { Vol. 9, No. 4, pp. 201-216, August 2017 } \\
\end{array}$} \\
\hline \multirow[t]{3}{*}{ Family Income } & $<=100,000$ & $\begin{array}{l}-2.5^{* * *} \\
(0.59)\end{array}$ & $\begin{array}{l}-2.61^{* * * *} \\
(0.59)\end{array}$ \\
\hline & Between 100,000 and 200,000 & $\begin{array}{l}0.65 \\
(0.50)\end{array}$ & $\begin{array}{l}0.78 \\
(0.50)\end{array}$ \\
\hline & $>=200,000$ & 0 & 0 \\
\hline \multirow[t]{5}{*}{ Health state } & Excellence & $\begin{array}{l}-4.4^{* * *} \\
(1.57)\end{array}$ & $\begin{array}{l}-4.13^{* * *} \\
(1.57)\end{array}$ \\
\hline & Very good & $\begin{array}{l}-1.7^{* * * *} \\
(0.46)\end{array}$ & $\begin{array}{l}-1.72^{* * *} \\
(0.46)\end{array}$ \\
\hline & Good & 0 & 0 \\
\hline & Fair & $\begin{array}{l}-3.1^{* * *} \\
(0.82)\end{array}$ & $\begin{array}{l}-3.70^{* * * *} \\
(0.83)\end{array}$ \\
\hline & Poor & $\begin{array}{l}-4.2^{* * * *} \\
(1.18)\end{array}$ & $\begin{array}{l}-4.46^{* * *} \\
(1.18)\end{array}$ \\
\hline \multirow[t]{2}{*}{ Net positive affect } & & $0.08^{*}$ & $\begin{array}{l}0.04 \\
(0.04)\end{array}$ \\
\hline & & $(0.04)$ & \\
\hline R Square & & 0.508 & 0.514 \\
\hline Observation & & 787 & 787 \\
\hline
\end{tabular}

\section{Discussion and Conclusion}

As aforementioned, the experiment is well designed. However, it has to be pointed out that typicality of the sample of this paper, which based on college student, may be questionable, because it cannot well-represent the Chinese people. College students mostly are from middle class family, and the middle class may have a different risk preference and emotional reaction pattern from the financial limited groups. Besides that, the paper demonstrated that positive emotion can also negatively affect Chinese respondents' time preference, though in a smaller amount, which implies that, compared to American counterparts, the Chinese respondents in this research shows less TP changes due to positive emotional changes. The mood inducement method that customized for this experiment is proved effective for Chinese respondents. Moreover, risk preference also plays a role in affecting Chinese people's time preference. Specifically, the result suggests that risk neutral people, compared to risk-averse people, has a lower time preference. Also, a positive emotion seemingly enlarges this tendency, indicating that, when happier, Chinese respondents who are risk neutral will behave relatively more patient. Fourthly, male participants tend to show a lowered time reference than females. This is also in accordance with the literature. That is to say, Chinese males are more "patient" than females.

Fifthly, differences in family income do show a negative relationship with time preference. That is to say, students from lower income tend to have higher time preference than average level. This is in accordance with the literature review which indicates that wealthiness and patience (low time preference) have a reciprocal causation. i.e. Patience promotes success, and richness nurtures forbearance. Finally, the effect of the health status is a tricky one. From the unhealthiest state people to the neutral state respondents, the healthier a person reported, the lower the time reference. The significance of this self-report variable is high, and this result is also in accordance with the reviews of the literature, which indicates that people who are really unhealthy tend to more focus on the present, rather than the future. However, from the neutral- to the healthiest state people, the tendency is reversed. This phenomenon needs a further explanation. In the future, 
negative emotions should also be put into considerations. Due to the limitation of time, the researchers did not accomplish the experiment concerning about negative emotions. If time permitted, experiments concerning about different but more specific kinds of emotions should also be conducted. (For example, both "interested" and "satisfied" are seen as positive emotions, but they may induce different time preference choices.)

Additionally, there are two alternative possible explanations. Firstly, risk preference and emotion inducement may have a joint effect. Although the paper wrote by Ifcher and Zarghamee (2011) did not emphasize on people's personality factors, but it is logical to argue that individuals with a higher tendency of risk seeking will behave differently from people who adverse risks. Therefore, the researchers of this paper added a professional risk-taking test to measure participants' risk preference and to examine the relationship between the personalities and the time preference. However, it should also argue that those risk-seeking people may be easier to be induced or inflamed by inducement of positive emotions. They tend to obtain a higher degree of positive moods during the experiment than those risk aversion people so as to cause a higher discounting rate. i.e. a joint effect factor may exist here. Secondly, the smaller-than-American discounting rate may be alternatively caused by a lower purchasing power of the currency. Compared to payment dominated by US dollar in the experiment conducted in the US, the payment in this paper is dominated in RMB. Although we pay the same face value as the US experiment, the real purchasing of the payment is weaker. People may behave more indifferent, therefore, about the changes.

\section{Reference}

Ainslie, G. \& Haendel, V. (1983). The motives of the will. Etiologic aspects of alcohol and drug abuse, 3, 119140.

Andersen, S. \& Harrison, G. W. \& Lau, M. I. \& Rutström, E. E. (2008). Eliciting risk and time preferences. Econometrica, 76(3),583-618.

Becker, G. M., Degroot, M. H. \& Marschak, J. (1964). Measuring Utility by a Single-Response Sequential Method. Behavioral Science, 9(3), 226-32.

Benhabib, J. \& Bisin, A. (2005). Modeling internal commitment mechanisms and self-control: A neuroeconomics approach to consumption-saving decisions. Games and Economic Behavior, 52(2), 460-492.

Benzion, U., Rapoport, A. \& Yagil, J. (1989). Discount rates inferred from decisions: An experimental study. Management science, 35(3), 270-284.

Borghans, L., Duckworth, A. L., Heckman, J. J. \& Ter Weel, B. (2008). The economics and psychology of personality traits. Journal of Human Resources, 43(4), 972-1059.

Caplin, A. \& Leahy, J. (2001). Psychological expected utility theory and anticipatory feelings. Quarterly Journal of economics, 116(1), 55-79.

Chiu, R. K. \& Kosinski, F. A. (1994). Is Chinese conflict-handling behavior influenced by Chinese values? Social Behavior and Personality: an international journal, 22(1), 81-90.

Coller, M. \& Williams, M. B. (1999). Eliciting individual discount rates. Experimental Economics, 2(2), 107127.

Croson, R. \& Gneezy, U. (2009). Gender differences in preferences. Journal of Economic literature, 47(2), 448474.

DeSteno, D., Li, Y., Dickens, L. \& Lerner, J. S. (2014). Gratitude A Tool for Reducing Economic Impatience. Psychological science, 0956797614529979.

Fishburn, P. C. \& Rubinstein, A. (1982). Time preference. International Economic Review, 23(2), 677-694.

Fisher, I. (1930). The theory of interest. New York, Macmillan.

Frederick, S., Loewenstein, G. \& O'donoghue, T. (2002). Time discounting and time preference: A critical review. Journal of economic literature, 40(2), 351-401.

Fuchs, V. R. (1980). Time preference and health: an exploratory study. Victor R. Fuchs. (Eds) Economic Aspects of Health, (pp. 93-120). Chicago: University of Chicago Press.

Gross, J. J. \& Levenson, R. W. (1995). Emotion elicitation using films. Cognition \& Emotion, 9(1), 87-108.

Gul, F. \& Pesendorfer, W. (2001). Temptation and self-control. Econometrica, 69(6), 1403-1435.

Harrison, G. W., Lau, M. I. \& Williams, M. B. (2002). Estimating individual discount rates in Denmark: A field experiment. American economic review, 92(5), 1606-1617. 
Hausman, J. A. (1979). Individual discount rates and the purchase and utilization of energy-using durables. The Bell Journal of Economics, 10(1) 33-54.

Hermalin, B. E. \& Isen, A. M. (2001). The effect of affect on economic and strategic decision making. USC CLEO Research Paper, (C01-5).

Holcomb, J. H. \& Nelson, P. S. (1992). Another experimental look at individual time preference. Rationality and Society, 4(2), 199-220.

Holt, C. A. \& Laury, S. K. (2002). Risk aversion and incentive effects. American economic review, 92(5), 16441655.

Hsee, C. K. \& Weber, E. U. (1999). Cross-national differences in risk preference and lay predictions.

Ifcher, J. \& Zarghamee, H. (2011). Happiness and time preference: The effect of positive affect in a randomassignment experiment. The American Economic Review, 101(7), 3109-3129.

Isen, A. M. (2001). An influence of positive effect on decision making in complex situations: Theoretical issues with practical implications. Journal of consumer psychology, 11(2), 75-85.

Isen, A. M. (2007). Positive affect, cognitive flexibility, and self-control. Persons in context: Building a science of the individual, 48(3) 130-147.

Isen, A. M. (2008). Some ways in which positive affect influences decision making and problem solving. Handbook of emotions, 3, 548-573

Isen, A. M., Nygren, T. E. \& Ashby, F. G. (1988). Influence of positive affect on the subjective utility of gains and losses: it is just not worth the risk. Journal of personality and Social Psychology, 55(5), 710.

Jevons, H. S. (1905). Essays on economics. London, Macmilan.

Jevons, W. S. (1888). The theory of political economy. London, Macmillan.

Jiang, J. Chen, X. F. \& Chen, A. T. (2011). Approaches and New Progress of the Emotional Inducement. Journal of Xinan Normal University, 36(1), 209-214.

Jin, X. (2009). Research on the measurement of video emotion inducement approaches (Master's thesis, The Second Military Medical University).

Kahneman, D. \& Tversky, A. (1979). Prospect theory: An analysis of decision under risk. Econometrica: Journal of the Econometric Society, 47(2) 263-291.

Keltner, D., Haidt, J. \& Shiota, M. N. (2006). Social functionalism and the evolution of emotions. Evolution and social psychology, 4, 115-142. London: Routledge Press.

Kirby, K. N. (1997). Bidding on the future: evidence against normative discounting of delayed rewards. Journal of Experimental Psychology: General, 126(1), 54.

Kirby, K. N. \& Maraković, N. N. (1995). Modeling myopic decisions: Evidence for hyperbolic delay-discounting within subjects and amounts. Organizational Behavior and Human Decision Processes, 64(1), 22-30.

Laibson, D. (1997). Golden eggs and hyperbolic discounting. The Quarterly Journal of Economics, 112(2), 443477.

Lerner, J. S., Li, Y. \& Weber, E. U. (2012). The financial costs of sadness. Psychological science, 0956797612450302.

Leung, K. \& Lind, E. A. (1986). Procedural justice and culture: Effects of culture, gender, and investigator status on procedural preferences. Journal of Personality and Social Psychology, 50(6), 1134.

Loewenstein, G. \& Prelec, D. (1992). Anomalies in intertemporal choice: Evidence and an interpretation. The Quarterly Journal of Economics, 81, 573-597

Loewenstein, G. (1996). Out of control: Visceral influences on behavior. Organizational behavior and human decision processes, 65(3), 272-292.

Loewenstein, G. (2000). Emotions in economic theory and economic behavior. American economic review, 10, 426-432).

Mischel, W., Shoda, Y. \& Rodriguez, M. I. (1989). Delay of gratification in children. Science, 244(4907), 933938.

O'Donoghue, T. \& Rabin, M. (1999). Addiction and self-control. Addiction: Entries and exits, 24(2) 169-206.

Peng, Y. S. (2012). Study on dynamic parameters of emotional response time] (Master's thesis, Capital Normal University).

Rabin, M. \& Thaler, R. H. (2001). Anomalies: Risk aversion. The Journal of Economic Perspectives, 15(1), 219232. Retrieved at 2015-4-18 12:49:24. From http://search.proquest.com/docview/212075586?accountid=38789 
Riedl, A. M. \& Wölbert, E. M. (2013). Measuring time and risk preferences: reliability, stability, Domain Specificity (No. 041). Center for Economic Studies and Ifo Institute, Netherlands. From: http://ssrn.com/abstract $=2302494$

Rubinstein, A. (2000). Is It Economics and Psychology The Case of Hyperbolic Discounting. Tel Aviv University, the EitanBerglas School of Economics. International economic review, 104(4), 1207 1216.

Russell, J. A. \& Yik, M. S. (1996). Emotion among the Chinese.

Samuelson, P. A. (1937). A note on measurement of utility. The Review of Economic Studies, 4(2), 155-161.

Senior, N. W. (1836). An outline of the science of political economy. W. Clowes and Sons, Stamford Street.

Tanaka, T., Camerer, C. \& Nguyen, Q. (2010). Risk and time preferences: Experimental and household survey data from Vietnam. American Economic Review, 100(1), 557 - 571

Thaler, R. (1981). Some empirical evidence on dynamic inconsistency. Economics Letters, 8(3), 201-207.

Thaler, R. H. \& Shefrin, H. M. (1981). An economic theory of self-control. The Journal of Political Economy, $89(2), 392-406$.

Warner, J. T. \& Pleeter, S. (2001). The personal discount rate: Evidence from military downsizing programs. American Economic Review, 91(1), 33-53.

Westermann, R., Stahl, G. U. N. T. E. R. \& Hesse, F. (1996). Relative effectiveness and validity of mood induction procedures: analysis. European Journal of social psychology, 26, 557-580.

Zaleskiewicz, T. (2001). Beyond risk seeking and risk aversion: personality and the dual nature of economic risk taking. European Journal of Personality, 15(S1), pp. S105 - S122. doi:10.1002/per.426

Zhou Y. A., Zuo, C. Y., Chen Y. F., Lian H. Q. \& Ye, H. (2012). Experimental study with social preferences of individual risk aversion. Management World, 6, 86-95.

\begin{tabular}{|c|c|c|c|c|}
\hline \multicolumn{5}{|c|}{ Appendix 1 Experiment Questions } \\
\hline No. & Lottery A $(2,1.6)$ & choice & Lottery B $(3.85,0.10)$ & choice \\
\hline 1 & $11 / 10$ Get 2 vs $9 / 10$ Get 1.6 & & $1 / 10$ Get 3.85 vs $9 / 10$ Get 0.10 & \\
\hline 2 & $2 / 10$ Get 2 vs $8 / 10$ Get 1.6 & & $2 / 10$ Get 3.85 vs $8 / 10$ Get 0.10 & \\
\hline 3 & $3 / 10$ Get 2 vs $7 / 10$ Get 1.6 & & $3 / 10$ Get 3.85 vs $7 / 10$ Get 0.10 & \\
\hline 4 & $4 / 10$ Get 2 vs $6 / 10$ Get 1.6 & & $4 / 10$ Get 3.85 vs $6 / 10$ Get 0.10 & \\
\hline 5 & $5 / 10$ Get 2 vs $5 / 10$ Get 1.6 & & $5 / 10$ Get 3.85 vs $5 / 10$ Get 0.10 & \\
\hline 6 & $6 / 10$ Get 2 vs $4 / 10$ Get 1.6 & & $6 / 10$ Get 3.85 vs $4 / 10$ Get 0.10 & \\
\hline 7 & 7/10 Get 2 vs $3 / 10$ Get 1.6 & & $7 / 10$ Get 3.85 vs $3 / 10$ Get 0.10 & \\
\hline 8 & $8 / 10$ Get 2 vs $2 / 10$ Get 1.6 & & $8 / 10$ Get 3.85 vs $2 / 10$ Get 0.10 & \\
\hline 9 & $9 / 10$ Get 2 vs $1 / 10$ Get 1.6 & & $9 / 10$ Get 3.85 vs $1 / 10$ Get 0.10 & \\
\hline 10 & $10 / 10$ Get 2 vs $0 / 101.6$ & & $10 / 10$ Get 3.85 vs $0 / 10$ Get 0.10 & \\
\hline
\end{tabular}

Term B

What amount of money, ¥p, if you could receive today would bring you the same utility if $\$ \mathrm{~m}$ paid to you in $\mathrm{t}$ days?

$\mathrm{m}=¥ 24.7$

$\mathrm{t}=7 \quad \mathrm{P}=$

$\mathrm{m}=¥ 30.8$

$\mathrm{t}=24 \quad \mathrm{P}=$

$\mathrm{m}=¥ 15.2$

$\mathrm{t}=24 \quad \mathrm{P}=$

$\mathrm{m}=¥ 24.7$ 


$$
\begin{array}{ll}
t=24 & P= \\
m=¥ 30.8 & \\
t=1 & P= \\
m=¥ 24.7 & \\
t=1 & P= \\
m=¥ 24.7 & \\
t=41 & P= \\
m=¥ 15.2 & \\
t=1 & P= \\
m=¥ 15.2 & \\
t=41 & P= \\
m=¥ 24.7 & \\
t=35 & P= \\
m=¥ 30.8 & \\
t=7 & P= \\
m=¥ 15.2 & \\
t=7 & P= \\
m=¥ 15.2 & \\
t=35 & P= \\
m=¥ 30.8 & \\
t=35 & P= \\
m=¥ 30.8 & \\
t=41 & P=
\end{array}
$$

Term C

Please rate from 1 (Have the opposite feelings as the described) to 5 (Have the same feeling as the described) to describe the degree to which you are feeling.

Please describe your degree of feeling of being interested(有意思). (please circle only one number)

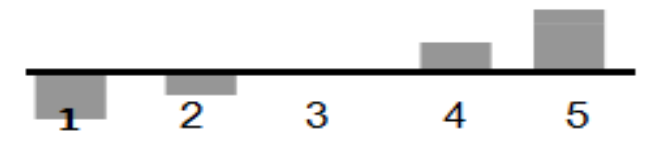

Please describe your degree of being excited(兴奋).(please circle only one number)

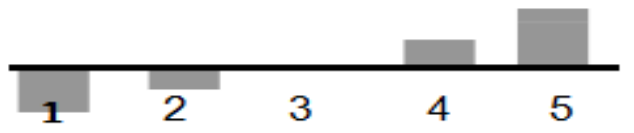

Please describe your degree of being enthusiasm（有热情）.(please circle only one number)

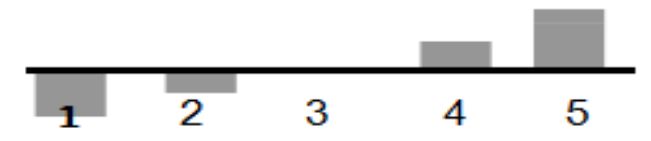

Please describe your degree of being activated（被激活）.(please circle only one number)

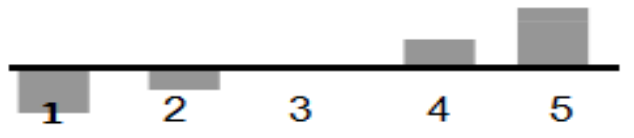

Please describe your degree of being distressed（沮丧）.(please circle only one number)

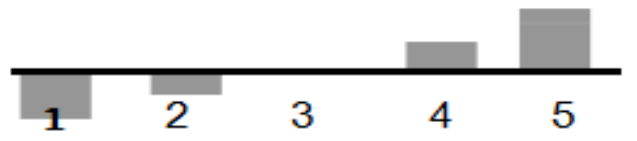

Please describe your degree of being nervous（神经紧张）.(please circle only one number) 


\section{Journal of Economics and Behavioral Studies (ISSN: 2220-6140)}

Vol. 9, No. 4, pp. 201-216, August 2017

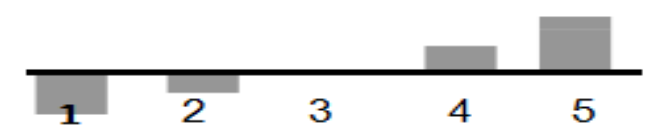

Please describe your degree of being upset（不安）.(please circle only one number)

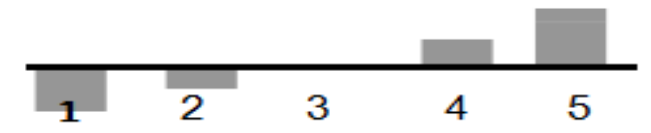

Item D

Watched short funny video or not

$\square$ Yes $\quad \square$ No

Gender (check $\sqrt{ }$ only one )

$\square$ Female $\quad \square$ Male

Family income (check $\sqrt{ }$ only one)

$\square<¥ 100,000$ ロbetween $¥ 100,000$ and $¥ 200,000 \square>¥ 200,000$

Health

$\square$ Excellent $\square$ Very good $\square$ Good $\square$ Fair $\square$ Poor 